\title{
Estimating Friction Coefficient and Fraction of Sliding in Friction Stir Welding
}

\author{
Zhihan Zhang, Wenya $\mathrm{Li}^{*}$ and Jinglong $\mathrm{Li}$
}

\author{
State Key Laboratory of Solidification Processing, Shaanxi Key Laboratory of Friction Welding Technologies, \\ Northwestern Polytechnical University, Xi'an 710072, Shaanxi, PR China
}

Received 21 November 2013; Accepted 5 March 2014

\begin{abstract}
The heat generation, contact state, material flow and friction coefficient are all intertwined during friction stir welding (FSW) because of the fully thermomechanical coupling nature of FSW. The value of friction coefficient and the fraction of sliding will dominate heat generation which is the driving force to make the FSW process successful. This work detailedly clarified how to roughly estimate the fraction of sliding and friction coefficient at the tool/workpiece interface. Results showed that friction coefficients in FSW of various materials were in a range of 0.2-0.56. The fraction of sliding was significantly affected by friction coefficient. The fraction of sliding was in a range of about $73-88 \%$ for FSW of Al1 100-H14 alloy and about 38-65\% for FSW of A17050-T7451 alloy. Moreover, the fraction of sliding increased with decreasing heat input.
\end{abstract}

Keywords: Friction stir welding, Heat generation, Contact state, Friction coefficient

\section{Introduction}

Friction stir welding (FSW) is quite different from conventional arc welding, laser welding and electron beam welding since these employ an external heat source of specified power, whereas the FSW process itself generates the heat. During FSW the joining process is significantly influenced by the heat generation, heat flow and material flow $[1,2]$. The heat input is therefore a complex function of the process parameters, such as welding speed, rotating speed, materials being welded, and tool geometry. The total heat input $\left(Q_{\text {total }}\right)$ in numerous thermal models of FSW is generally estimated by the following expression [3].

$$
Q_{\text {total }}=\frac{2}{3} \pi \tau_{\text {contact }} \omega\left[\begin{array}{l}
\left(R_{\text {shoulder }}^{3}-R_{\text {probe }}^{3}\right) \\
(1+\tan \alpha)+R_{\text {probe }}^{3} \\
+3 R_{\text {probe }}^{2} H_{\text {probe }}
\end{array}\right]
$$

where $\tau_{\text {contact }}$ is the contact shear stress, $\omega$ is the rotating speed of tool, $\alpha$ is the cone angle in the conical shoulder surface, $R_{\text {shoulder }}$ is the radius of tool shoulder, $R_{\text {probe }}$ is the radius of tool probe, and $H_{\text {probe }}$ is the length of tool probe. The contact shear stress, $\tau_{\text {contact }}$, is not a constant during FSW, which depend on which contact states present at the tool/workpiece interface. Results in open literature [4-6] have proved that the actual contact state at the tool/workpiece interface during FSW is a combination of sliding and sticking rather than complete sticking condition [7-9] or complete sliding condition [10-12]. Hence the contact shear stress at the tool/ workpiece interface during FSW should be calculated by the following correlation:

$$
\tau_{\text {contact }}=(1-\delta) \tau_{\text {yield }}+\delta \mu P
$$

where $\tau_{\text {yield }}$ is the yield shear stress, $\delta$ is the fraction of sliding, $\mu$ is the friction coefficient and $P$ is the contact pressures. In FSW the contact pressure, $P$, can be approximately estimated by the following equation [3]:

$$
P=\frac{F}{\pi R_{\text {shoulder }}^{2}}
$$

where $F$ is the experimental axial force. It is concluded from Eqs. (1) and (2) that the value of friction coefficient and fraction of sliding will dominate heat generation during FSW. The fraction of sliding and friction coefficient are thus the most critical part for understanding heat generation in the FSW process and developing a correct model. Lots of experimental and computational researches $[1,2]$ on heat generation, material flow behavior and temperature field have been performed in the past decade, which have provided significant insight into the interesting features of materials flow and temperature distribution, but at the present time few researchers focus on $\delta$ and $\mu$. This work, therefore, aims to clarify how to roughly estimate $\delta$ and $\mu$ at the tool/workpiece interface in the FSW process.

\section{Analytical models for estimating $\delta$ and $\mu$}


In general, $\mu$ was assumed as a constant value in the range of 0.3-0.5 in numerous models of FSW [4,10-12]. Particularly, Kalya et al. [13] reported that $\mu$ range from 0.35 to 0.57 during FSW of 5182 aluminum alloy and from 0.6 to 1.3 during FSW of F-357 aluminum alloy, which is quite different with the generally assumed values. It is necessary for understanding the mechanism of heat generation to estimate $\mu$. Therefore, a following relationship proposed by Mishra et al. [14] was employed in this work to compute $\mu$.

$$
\mu=\frac{3 M_{\text {exp }}}{2 F R_{\text {shoulder }}}
$$

where $M_{\text {exp }}$ is the measured torque by experiment.

In order to estimate the relative contribution of sliding and sticking to heat generation, in our previous study [15] $\delta$ was defined as

$$
\delta=\frac{M_{\text {exp }}-M_{\text {sticking }}}{M_{\text {sliding }}-M_{\text {sticking }}}
$$

where $M_{\text {sticking }}$ and $M_{\text {sliding }}$ are the torque under complete sticking and complete sliding respectively, which can be calculated from the following analytical model based on the shear stress at the surface of the tool in contact with the workpiece [15].

$$
M=\oint_{A} r \times \tau_{\text {contact }} d A
$$

where $r$ is the distance of differential area $d A$ to the centre of the tool.

\section{Results and discussion}

Friction coefficients, $\mu$, for FSW of various materials under different process parameters were calculated by Eq. (4) based on the data available on the open literature [3,15-20]. The relationship between $\mu$ and pseudo-"heat input" (HI) was shown in Fig. 1. HI was given as

$$
H I=\frac{R_{\text {shoulder }} \omega^{2}}{v \times 10^{4}}
$$

where $v$ is welding speed. It is clearly seen that $\mu$ is in the range of 0.2-0.56 during FSW. Moreover, $\mu$ is quite different under different HI for FSW of the same material. These facts indicate that changing the process parameter or material being welded may result in the significant difference in the contact condition and heat generation during FSW. For example, the temperature curves obtained [11,21,22] by numerical analyses under different $\mu$ have proved the remarkable influence of $\mu$ on the heat generation. However, quantitative study of the effects of different variables on the contact condition and heat generation is significantly difficult owing to fully coupled mechanism of FSW and lack of adequate description on the assigning weighting factors to the interactions among variables. Therefore, in spite of the apparent simplicity of the FSW process, there are still many aspects of the process that remain unexplained.

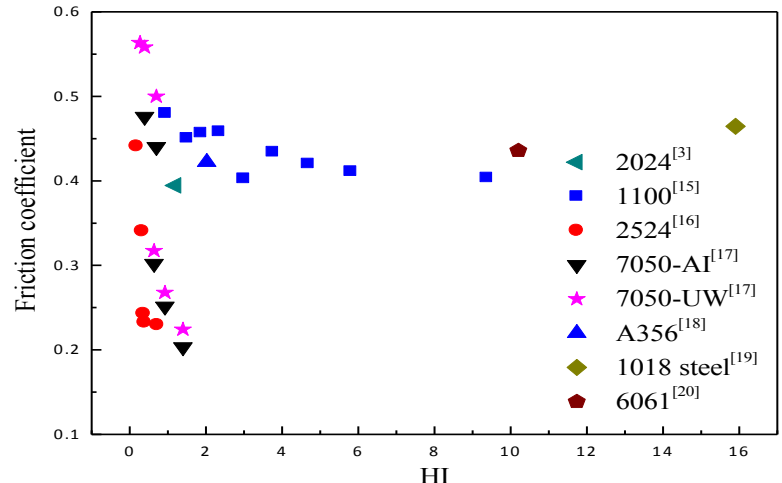

Fig. 1. Variation of friction coefficient with HI in FSW of various materials. (AI denote in air and UW denote under water)

Once the $\mu$ was determined and the contact condition was assumed to be complete sliding $(\delta=1)$ or complete sticking $(\delta=0)$, the $M_{\text {sliding }}$ or $M_{\text {sticking }}$ can be calculated by Eq. (6). In the present research, $M_{\text {slidin }}, M_{\text {sticking }}$ and $\delta$ under different process parameters during two aluminum alloys of FSW were calculated and were shown in Fig.2. It is found from Fig. 2(a) that $M_{\text {exp }}$ were smaller that $M_{\text {sliding }}$ but larger than $M_{\text {sticking }}$ under the same HI. This indicates that complete sliding or complete sticking is not appropriate for estimating heat generation of FSW. The combination of sliding and sticking is, therefore, more suitable as the facts reported in the literature [4-6]. Furthermore, with increasing HI $M_{\text {exp }}$ and $M_{\text {silding }}$ decrease quickly owing to the decrease of $\tau_{\text {contact }}$ caused by temperature rising. It is observed from Fig. 2(b) that $\delta$ is in range of about $73-88 \%$ for $1100-\mathrm{H} 14$ aluminum alloy and about $38-65 \%$ for $7050-T 7451$ aluminum alloy. These facts indicate that the relative contribution of sliding and sticking to heat generation is quite different during FSW of different materials, which will dominate the temperature increase within the workpiece depending on the material being welded and process parameters.
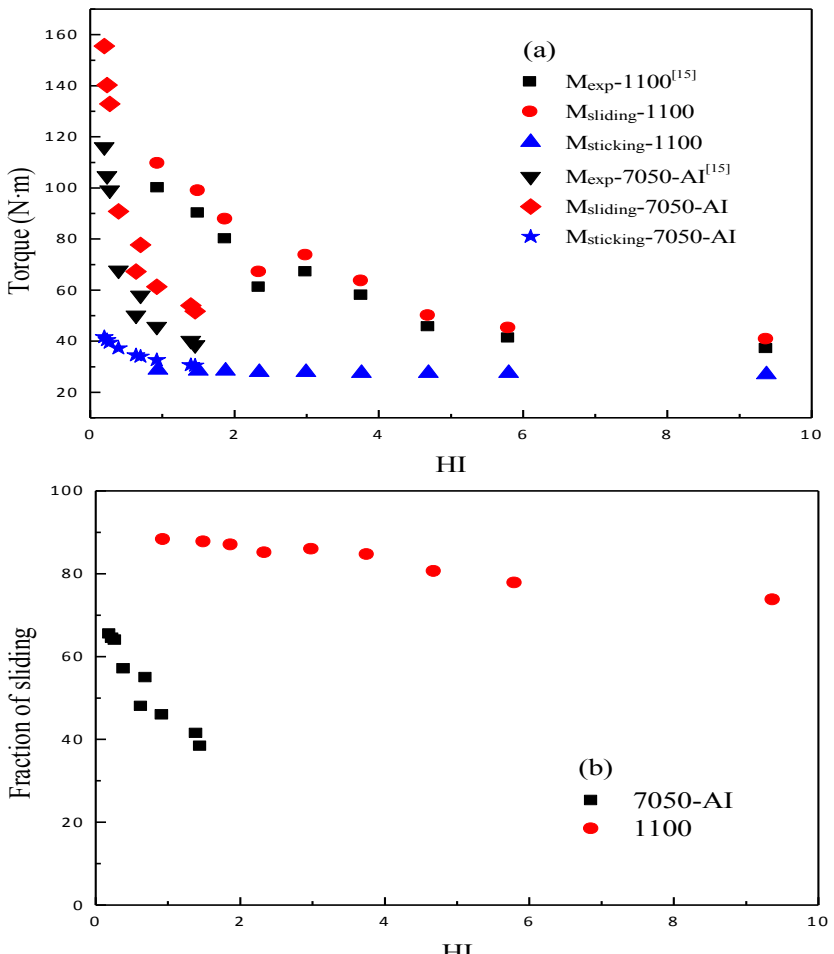

Fig. 2. Variation of torque (a) and fraction of sliding (b) with HI. 
In order to clarify the effect of $\mu$ on $\delta, M_{\text {sliding }}$ and $\delta$ estimated in this research were compared with the corresponding results available in the open literature [15] as presented in Fig. 3. It should be noted that $\mu$ in the literature [15] was a constant (0.5) for various process parameters but it is varying in this work as shown in Fig.1. It is obviously observed that $M_{\text {sliding }}$ was overestimated in reference [15] owing to the high value of $\mu$, which resulted in the lower $\delta$. During the FSW process, the heat generation, contact state, flow stress and friction coefficient are all intertwined. Therefore the variation of $\mu$ will give rise to the change of flow stress, the thermal history, material flow, contact state and vice versa, which are in direct response to the mechanism of FSW. Friction between surfaces has been extensively studied in the past and it has been shown that friction is strongly dependent on local conditions. For sliding friction between clean metallic surfaces at high temperatures, the friction coefficient has been shown generally to decrease with increasing temperature [23]. A similar work does not exist for the much younger FSW. In the initial modeling efforts the friction coefficient was artificially set without any reference. Lots of modeling efforts primarily relies on either the Coulomb friction model or the constant shear model. Hence it would be ideal to obtain the adequate information on the variations of friction coefficient and fraction of sliding during FSW, which is most useful for understanding the nature of FSW.

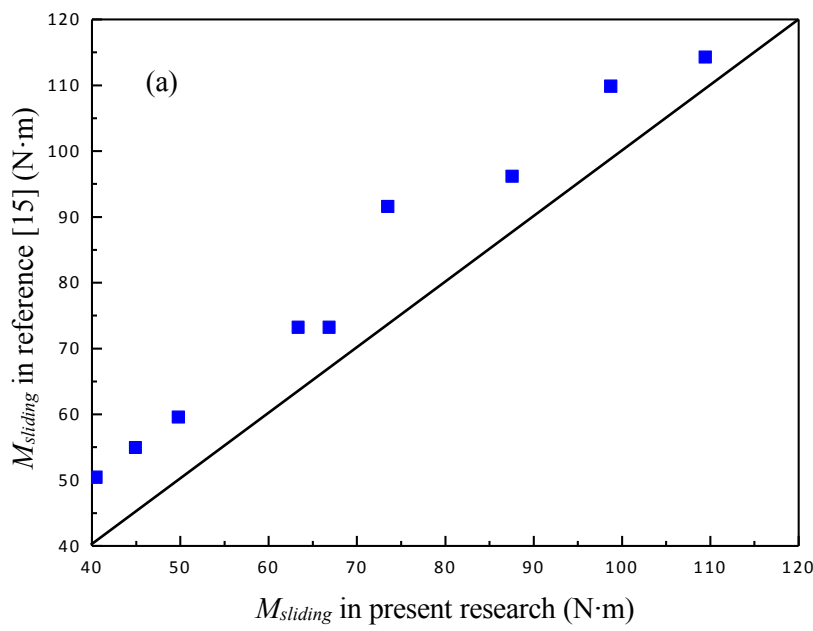

\section{References}

1. R.S. Mishraa, Z.Y. Ma, Mater. Sci. Eng. R 50 (2005) 1-78.

2. A. Simar, Y. Bréchet, B. de Meester, A. Denquin, C. Gallais, T. Pardoen, Prog. Mater. Sci. 57 (2012) 95-183.

3. H. Schmidt, J. Hattel, J. Wert, Modelling Simul. Mater. Sci. Eng. 12 (2004) 143-157.

4. R. Nandan, G. G. Roy, T. J. Lienert, T. Debroy, Acta Mater. 55 (2007) 883-895.

5. R. Nandan, G. G. Roy, T. Debroy, Metall. Mater. Trans. A 37 (2006, A) 1247-1259.

6. R. Nandan, G. G. Roy, T. J. Lienert, T. Debroy, Sci. Technol. Weld. Join. 5 (2006) 526-537.

7. W.Y. Li, Z.H. Zhang, J.L. Li, Y.J. Chao, J. Mater. Eng. Perform. 21 (2012) 1849.

8. Z.H. Zhang, W.Y. Li, J.L. Li, Y.J. Chao, J. Mater. Eng. Perform. 9 (2013) 2446-2450.

9. M.Z.H. Khandkar, J.A. Khan, A.P. Reynolds, Sci Technol. Weld. Join. 8 (2003) 165-174.

10. Y.J. Chao, X. Qi, Ther, J. Mater. Process. Manuf. Sci. 7 (1998)

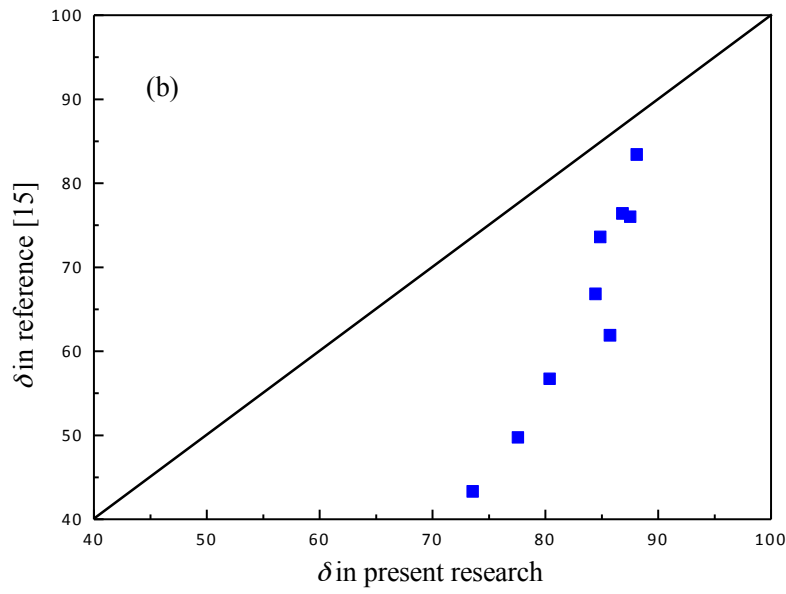

Fig. 3. Comparison of $M_{\text {sliding }}$ (a) and $\delta$ (b) with corresponding reported results.

\section{Conclusions}

In the present work, the friction coefficient and fraction of sliding at the tool/workpiece interface during FSW were estimated. The calculated results were compared and discussed in detail, which provides the following highlights:

(1) Friction coefficients in FSW of various materials were roughly calculated and were in the range of $0.2-0.56$. Changing the process parameter or material being welded will result in the variation of friction coefficient during the FSW process.

(2) The fraction of sliding was significantly affected by friction coefficient. Fraction of sliding was in a range of about $73-88 \%$ for FSW Al1100-H14 alloy and about $38-65 \%$ for FSW A17050-T7451 alloy. Moreover, the fraction of sliding increased with decreasing heat input in FSW.

\section{Acknowledgements}

The authors would like to acknowledge the financial supports from the National Natural Science Foundation of China (51005180), the Fok Ying-Tong Education Foundation for Young Teachers in the Higher Education Institutions of China (131052), the Fundamental Research Fund of NPU (JC201233) and the 111 Project (B08040).

$$
\text { 215-233. }
$$

11. M. Zahedul, H. Khandkar, J.A. Khan, J. Mater. Process. Manuf. Sci. 10 (2001) 91-105.

12. M. Song, R. Kovacevic, Int. J. Mach. Tools. Manuf. 43 (2003) 605-615.

13. P. Kalya, K. Krishnamurthy, R.S. Mishra, J.A. Baumann, Friction Stir Welding and Processing IV, TMS, Orlando, FL, 2007, 113.

14. K.J. Colligan, R.S. Mishra, Scripta Mater. 58 (2008) 327-331.

15. J.W. Qian, J. L. Li, J.T. Xiong, F. S. Zhang, W. Y. Li, X. Lin, Science and Technology of Welding and Joining, 2012, 17, 338-341.

16. J.H. Yan, M.A. Sutton, A.P. Reynolds, Sci. Technol. Weld. Join. 10 (2005) 725-736.

17. P. Upadhyay, A.P. Reynolds, Mater. Sci. Eng. A 527 (2010) 1537-1543.

18. S. Cui, Z.W. Chen, J.D. Robson, Int. J. Mach. Tools. Manuf. 50 (2010) 1023-1030

19. T.J. Lienert, W.L. Stellwag, JR., B.B. Grimmett, R.W. Warke, 
Zhihan Zhang, Wenya Li and Jinglong Li/Journal of Engineering Science and Technology Review 7 (3) (2014) 192 - 195

Weld. J. 2003 1-9

20. W.R. Longhurst, A.M. Strauss, G.E. Cook, P.A. Fleming, Int. J. Adv. Manuf. Tech. 51 (2010) 905-913.

21. A. Simar, J. Lecomte-Beckers, T. Pardoen, B. de Meester, Sci. Technol. Weld. Join. 11 (2006) 170-177.
22. O. Frigaard, O. Grong, O.T. Midling, Metal. Mater. Trans. A 2001;32:1189-200.

23. F.P. Bowden, T.P. Hughes, Proc. R. Soc. London, Ser. A 172 (1939) 263-279. 